become narrowed by neointimal hyperplasia, particularly at the anastomotic site. ${ }^{2}$

Once again we return to our original conclusion (shared by Dr Rossouw; 1984; 51: 237) of choosing the largest possible graft that can be tailored to the anatomy.

P H Kay,

R E Franks,

A Capuani,

C Lincoln,

\section{Chordal rupture: aetiology and natural history}

Sir,

We read with interest the recent review of chordal rupture from the Brompton Hospital (1983; 50: 3127). Primary "idiopathic" rupture accounted for a large majority of cases. We wish to draw attention to the possibility that some of these patients may have had mitral valve prolapse. This possibility cannot be excluded by the slight male predominance observed in this series of patients with chordal rupture. Although mitral valve prolapse is characterised by female predominance, some complications may be selective. Moreover, other biases may operate in a retrospective series.

In reviewing 134 patients with mitral valve prolapse we have found $15(11.2 \%)$ patients with echocardiographic signs of chordal rupture. ${ }^{1}$ In another series $7 \%$ of patients with mitral valve prolapse were found to have chordal rupture. ${ }^{2}$ We have since extended our series to include 264 patients with this condition. These patients were free of other cardiovascular or systemic disorders. Twenty eight (10.6\%) patients were found to have $M$ mode echocardiographic signs of chordal rupture. The majority of these patients had three or more echocardiographic signs of chordal rupture simultaneously, a feature which enhances the sensitivity and specificity of the echocardiographic diagnosis. ${ }^{1}$ In 24 patients the diagnosis was confirmed by cross-sectional echocardiography. Only eight patients had symptoms of sufficient severity to warrant intervention, and in all of these confirmation was obtained at operation. Of particular note were three patients who had previously been followed up for mitral valve prolapse and who later developed echocardiographic signs of chordal rupture. We were also surprised to note the appreciable proportion of patients who were asymptomatic or had only mild symptoms indistinguishable from those with uncomplicated mitral valve prolapse. Of related interest is a recent necropsy series of 90 patients with mitral valve prolapse. ${ }^{3}$ Twenty two patients were found to have chordal rupture, only five of whom had related
Brompton Hospital,

London SW3 6HP.

\section{References}

1 Norberg WJ, Tadavarthy M, Knight L, Nicoloff DM, Moller JH. Late hemodynamic and angiographic findings after ascending aorta-pulmonary artery anastomosis. I Thorac Cardiovasc Surg 1978; 76: 345-52.

2 Kay PH, Capuani A, Franks RE, Lincoln C. Experience with the modified Blalock-Taussig operation using polytetrafluoroethylene (Impra) grafts. Br Heart $\mathcal{F} 1983$; 49: 359-63.

endocarditis. Thus $17(18 \%)$ patients had chordal rupture with mitral valve prolapse as the only associated cardiac lesion. In most of these patients the diagnosis of chordal rupture had not been suspected before death. Although findings in necropsy series cannot be simply extended to a patient population in a cardiac clinic, the findings corroborate our impression that chordal rupture may be more prevalent than is commonly thought and that it is often unsuspected clinically.

Many reviews of chordal rupture are of retrospective surgical series. They thus lack detailed analyses of long term clinical history and previous findings including echocardiography. They are also biased in view of the necessary selection of severely symptomatic patients who require surgery. Many of the medical reviews of spontaneous chordal rupture are from a period in which mitral valve prolapse was not an established diagnosis and before echocardiographic signs of chordal rupture had been elaborated. They may thus also obscure the underlying conditions predisposing to chordal rupture and tend to be biased towards patients with significant symptoms and signs.

Although association does not prove causality, we believe our findings are suggestive. Future reviews of chordal rupture should attempt to exclude mitral valve prolapse before designating cases as "idiopathic" or primary. This subgroup of patients may possibly become smaller. An aetiological relation between mitral valve prolapse and chordal rupture will be shown by a prospective follow up of patients with mitral valve prolapse and suitable control subjects.
G Alpan,
E Grenadier,
A Palant,
Coronary Care Unit,
Department of Cardiology,
Carmel Hospital,
PO Box 7222, Mt Carmel, Haifa, Israel. 


\section{References}

1 Grenadier E, Alpan G, Keidar S, Palant A. The prevalence of ruptured chordae tendineae in the mitral valve prolapse syndrome. Am Heart $\mathcal{F}$ 1983; 105: 603-10.

2 Chandraratna PAN, Aronow WS. Incidence of ruptured chordae tendineae in the mitral valvuiar prolapse syndrome. Chest 1979; 75: 334-9.

3 Davies MJ, Moore BP, Braimbridge MV. The floppy mitral valve. Study of incidence, pathology, and complications in surgical, necropsy, and forensic material. $\mathrm{Br}$ Heart f 1978; 40: 468-81.

This letter was shown to the authors, who reply as follows:

Sir, We were very interested to see the continuing results of Drs Alpan, Grenadier, and Palant's echocardiographic survey of patients with mitral valve prolapse. As they mention, longitudinal studies of this type will give us the best information on the natural history of mitral valve prolapse, chordal rupture, and related conditions.

Their letter otherwise makes two main points: firstly, that mitral valve prolapse may well be a common cause (or at least an association) of chordal rupture; and, secondly, that the symptoms associated with chordal rupture may be non-existent or relatively mild. With regard to the first point it is true that many of our cases of idiopathic rupture occurred in the setting of a floppy mitral valve and would presumably have been classed as having mitral valve prolapse before the development of chordal rupture. Nevertheless, there were also a significant number of cases in which chordal rupture was associated with a relatively normal valve. It would have been more accurate to reserve the term spontaneous (or primary) rupture for this latter group, but because of the difficulties in detailed classification in a retrospective study we were unable to do this. Furthermore, any absolute division may be artificial in that there may well be a spectrum extending from myxomatous change affecting the chordae alone in the latter group to involvement of the valve and chordae in the former.

With regard to their second point we are in full agreement that chordal rupture is often not the dramatic clinical entity that is usually portrayed. Even our retrospective series with all the limitations that they mention was able to show a long, often very mild, history of symptoms in many of our patients. A prospective echocardiographic study will undoubtedly detect many more mild or asymptomatic cases of chordal rupture.
David B G Oliveira,
Renal Unit,
Royal Postgraduate Medical School,
Hammersmith Hospital,
London W12 0HS.

\section{Notices}

\section{Cardiac pacing and electrophysiology}

The Third Asian Pacific Symposium on cardiac pacing and electrophysiology will be held from 27 to 30 October 1985 at the Melbourne Hilton, Melbourne. Further information may be obtained from: Secretary-General, 3rd Asian-Pacific Symposium on Cardiac Pacing and Electrophysiology, Department of
Cardiology, Suite 3.5, Epworth Medical Centre, 62 Erin Street, Richmond 3121, Victoria, Australia.

\section{British Cardiac Society}

The Autumn Meeting will be held at the Wembley Conference Centre, London, on 3 and 4 December 1984 , and the closing date for receipt of abstracts was 15 August 1984.

The Annual General Meeting for 1985 will take place in Birmingham on 17 and 18 April 1985, and the closing date for receipt of abstracts will be 8 January 1985. 